Difficult Decisions

\title{
Anastomosis or stoma for low rectal cancer?
}

\author{
Christine Hall, Simon Rowley and John P. Neoptolemos
}

University Department of Surgery, Dudley Road Hospital, Dudley Road, Birmingham B18 7QH, UK.

\section{Introduction}

Approximately 7,700 new cases of rectal cancer were registered for men and women in England and Wales in $1984 .{ }^{1}$ It would be expected that almost $70 \%$ of these would be in the distal two thirds of the rectum, ${ }^{2}$ and about half of these would undergo curative resection. ${ }^{3}$ With the development of new techniques such as transanal coloanal anastomosis ${ }^{4}$ and the advent of the stapling gun, ${ }^{5}$ it is technically possible to restore gastrointestinal continuity in the majority of patients with rectal tumours undergoing elective surgery. Controversy exists as to whether sphincter saving resections (SSR) result in compromised control of local disease or overall survival.

\section{Choice of procedure}

By tradition, a rectal tumour situated up to $10 \mathrm{~cm}$ from the anal verge would be treated curatively by a synchronous combined abdomino-perineal excision of the rectum (APER), and there are many that hold the view today that this is still the best option. However, the idea that only APER can achieve adequate tumour clearance both distally and laterally has recently been questioned. Williams et al. in $1983^{\circ}$ examined 50 resected specimens histologically following APER paying specific attention to sections of the distal resection margin. It was demonstrated that $76 \%$ of specimens had no evidence of intramural tumour spread, $14 \%$ had spread of one centimetre or less and only 5 of the 50 specimens had distal spread beyond one centimetre. Moreover, these 5 cases had poorly differentiated Dukes' $\mathrm{C}$ tumours and hence formed a poor risk group. It was concluded that it was not always necessary to obtain a $5 \mathrm{~cm}$ margin of clearance distally thereby permitting an increased opportunity for sphincter saving procedures.

Similarly, Heald has shown that adequate lateral clearance can be achieved during SSR.,8 Thus it

Correspondence: J.P. Neoptolemos, M.A., M.D., F.R.C.S. Received: 24 October 1988 appears that it is technically feasible to preserve the sphincters with adequate distal and lateral clearance, but do the clinical results justify SSR as a routine approach?

\section{Mortality and morbidity}

A retrospective study from a single unit in Leeds reported a mortality rate within 28 days of operation of $10.8 \%$ in 93 patients undergoing APER and $9 \%$ in 78 patients having SSR. ${ }^{9}$ These findings were confirmed in the United Kingdom multicentre pros $\vec{\bullet}$ spective Large Bowel Cancer Study: 1,376 patien underwent APER and 598 a SSR with in-hospitai mortality rates of $8 \%$ and $7 \%$ respectively. ${ }^{10}$

Morbidity associated with each procedure is a more difficult parameter to compare. The main complication of SSR is anastomotic leakage with a reported incidence of between $3 \%$ and $8 \%{ }^{7,11}$ Because of this, some surgeons routinely perform a temporary defunctioning colostomy for all tumours below $7 \mathrm{~cm},{ }^{7}$ but evidence that this reduces overall morbidity is lacking. Late anastomotic disruption and stenosis at the site of the anastomosis are quite uncommon and stricture can usually be dealt with by simple dilatation. ${ }^{12,13}$

Complete breakdown of the perineal wound or persistent discharge from this site following APER can be particularly distressing. Moreover, it has been estimated that $50 \%$ of all colostomy patients follow- 윽 ing resection of neoplastic disease suffer stoma comp- $\rightarrow$ lications of stenosis, prolapse or paracolostomy hernia. ${ }^{14}$ Overall, threfore, there is little to choose between $N$ SSR and APER with respect to post-operative mortality and morbidity.

\section{Quality of life}

In 1927, Lockhart-Mummery wrote that 'a colostomy opening done through the rectus muscle supplied an amount of control over the evacuation both of faeces and flatus which was sufficient in the great majority to

(C) The Fellowship of Postgraduate Medicine, 1989 울 
enable them to live quite ordinary lives in the comfort and security from possible unpleasant accidents'. ${ }^{15}$ This view, which gained almost universal acceptance, has recently been challenged.

Devlin et al. showed in 1971 that of all patients who had had a colostomy for cancer, $89 \%$ had changed their working habits, less than $50 \%$ ate a normal diet and $25 \%$ were overtly depressed. ${ }^{16}$ Williams and Johnston from Leeds showed that $83 \%$ of patients after SSR were able to return to work, compared with only $45 \%$ of those after APER; sexual dysfunction was greater after APER (67\% vs $30 \%)$ as was depression (mean depression score 4.6 vs 2.8). Moreover, all the patients with colostomies were incontinent and $66 \%$ of them had problems with leakage from the appliance. ${ }^{17}$

Leeds were completely continent at one year with further subsequent improvement. ${ }^{17}$ This finding has been substantiated by other centres, not only after low anterior resection, but also after coloanal anastomoses. $^{18,19}$ It would appear on this evidence that preservation of the sphincter leads to a better quality of life.

\section{Survival and recurrence}

Despite the early scepticism, as more long term studies have been reported, it seems that the local recurrence rate and five year survival rate are similar for APER and SSR. Data is difficult to interpret, however, as there is a tendency for the lower more aggressive tumours to be dealt with by APER. Apart from two notable exceptions, ${ }^{10,20}$ most studies show that both the five year survival and the rate of local recurrence are comparable (Table I).

\section{Suture or staple?}

If we accept that an anastomosis can be performed safely, is there a demonstrable difference between the hand sewn and stapled technique? There are few randomized prospective trials of suture versus staple, ${ }^{27}$ but most sequential reports confirm that leak rates and local recurrence rates have not increased on using the stapling device. ${ }^{2}$ Although some would argue that a low anastomosis can be performed just as well using a suturing method as a stapling technique, the proportion of patients undergoing APER has dramatically decreased with the increasing use of staples. For example, the incidence of APER in the Large Bowel Cancer Study was $46 \%{ }^{10}$ compared to only $11 \%$ in the Basingstoke series. $^{8}$

\section{Coloanal anastomosis}

A few centres have reported the use of a coloanal anastomosis with a colonic J-pouch..$^{28,29}$ This improves rectal capacity with a concomitant decrease in bowel frequency, but the real clinical benefit remains unproven and requires further evaluation.

\section{Local therapy}

There is unquestionably a place for local curative treatment of early rectal cancers. Surgical excision is the most widely practised in this country, but fulguration, ${ }^{30}$ cryosurgery, ${ }^{31,32}$ electrocoagulation ${ }^{33}$ and intracavity irradiation ${ }^{34}$ are useful alternative approaches. A recent study from Rochester, New York, reports dramatic results using endocavitary irradiation. $^{35}$ Using a system which delivers high dose irradiation to the tumour with minimal irradiation of

Table I Comparison of clinical outcome following abdomino-perineal resection excision of rectum (APER) and sphincter saving resection (SSR)

\begin{tabular}{|c|c|c|c|c|c|c|c|c|c|c|}
\hline \multirow[b]{2}{*}{ Authors } & \multicolumn{5}{|c|}{ APER } & \multicolumn{5}{|c|}{$S S R$} \\
\hline & $\begin{array}{c}\text { No. } \\
\text { patients }\end{array}$ & $\begin{array}{l}\text { Operative } \\
\text { mortality }\end{array}$ & $\begin{array}{l}\text { Operative } \\
\text { morbidity }\end{array}$ & $\begin{array}{l}\text { Local } \\
\text { recurrence }\end{array}$ & $\begin{array}{l}5 \text { year } \\
\text { survival }\end{array}$ & $\begin{array}{c}\text { No. } \\
\text { patients }\end{array}$ & $\begin{array}{l}\text { Operative } \\
\text { mortality }\end{array}$ & $\begin{array}{l}\text { Operative } \\
\text { morbidity }\end{array}$ & $\begin{array}{c}\text { Local } \\
\text { recurrence }\end{array}$ & $\begin{array}{l}5 \text { year } \\
\text { survival }\end{array}$ \\
\hline Deddish et al. $1961^{21}$ & 236 & - & - & $14.4 \%$ & - & 65 & - & - & $9.2 \%$ & - \\
\hline Morson et al. $1963^{22}$ & 1,238 & - & - & $9.7 \%$ & - & 177 & - & - & $7.3 \%$ & - \\
\hline † Nicholls et al. $1979^{23}$ & 112 & - & - & - & $74 \%$ & 87 & - & - & - & $71 \%$ \\
\hline McDermott et al. $1982^{24}$ & 107 & $5.6 \%$ & - & $16.8 \%$ & $71 \%$ & 310 & $5.8 \%$ & - & $19.0 \%$ & $68 \%$ \\
\hline †Luke et al. $1983^{25}$ & 36 & - & - & $22.2 \%$ & - & 44 & - & - & $22.7 \%$ & - \\
\hline Williams et al. $1984^{9}$ & 93 & $10.8 \%$ & - & $8.0 \%$ & $62 \%$ & 78 & $9.0 \%$ & - & $11.0 \%$ & $74 \%$ \\
\hline$†$ Phillips et al. $1984^{10}$ & 778 & $8.0 \%$ & - & $12.0 \% *$ & - & 598 & $7.0 \%$ & - & $18.0 \% *$ & - \\
\hline †Wolmark et al. $1986^{26}$ & 232 & - & - & $5.0 \%$ & $38 \%$ & 181 & - & - & $13.0 \%$ & $48 \%$ \\
\hline †Gillen et al. $1986^{11}$ & 45 & $2.2 \%$ & $60 \%$ & $14.7 \%$ & - & 55 & $7.2 \%$ & $55 \%$ & $25.0 \%$ & - \\
\hline
\end{tabular}

†APER and SSR groups matched for pathological stage/grade; ${ }^{*}$ Significant difference $\left(P<0.02, \chi^{2}\right)$ 
surrounding tissues, they achieved $95 \%$ local control of disease and a $93 \%$ five year survival rate. These results are superior to radical surgery although endocavitary irradiation is only suitable for approximately $20 \%$ of all rectal cancers. As with any local therapy aiming for cure, the lesions must be mobile Dukes' A lesions with no evidence of nodal metastases and well, or moderately well, differentiated. A poorly differentiated lesion which is locally invading and close to the sphincters is clearly not going to be suited to any form of curative local therapy or SSR. ${ }^{36}$

Rightly, many surgeons are reluctant to treat patients with rectal cancer by limited procedures, fearing such might not be curative. Most surgeons, if not totally confident on final histology that the lesion has been completely removed, would go on to perform a definitive major curative procedure. ${ }^{37}$

Unfortunately, very few lesions can be so clearly staged. Pre-operative sampling is poor at grading a tumour: only $52 \%$ of poorly differentiated tumours are so diagnosed on the pre-operative biopsies. ${ }^{38}$ In order to match the best possible curative procedure to the individual, it is essential that new techniques of local tumour assessment, estimation of distant disease and prognostic staging are explored.

\section{Local tumour assessment}

Digital rectal examination is still the most useful investigation available to every surgeon as it can assess the degree of local involvement with up to an $83 \%$ accuracy. However, this method is unable to determine the degree of spread with any useful accuracy. ${ }^{39}$

Nevertheless, digital rectal examination may be supplemented by other investigations. Conventional ultrasound of the pelvis is unsuitable in low rectal tumours because they are difficult to visualize. On the other hand, endoluminal ultrasound is emerging as a highly effective method of pre-operative staging: sensitivity in determining spread beyond the muscularis propria is $96 \% .{ }^{40}$ It appears to be easy to use with little inter-observer variation but clinical experience is limited. It has been shown to be superior to both digital rectal examination and computerized tomography. ${ }^{41}$ Whereas computerized tomography cannot differentiate the individual layers of the rectal wall as well as endoluminal ultrasound, it is a better modality for differentiating between malignant and inflammatory extra-rectal fixity. These are early days yet and further prospective comparative studies are required.

\section{Tumour markers}

Initially, it was thought that serum carcinoembryonic antigen (CEA) estimations would be unique in helping to stage colorectal cancer. Unfortunately, enthusiasm has now waned as it has become obvious that it is not 2 tumour-specific. It is insensitive as a marker of resec- $\bar{z}$ tability as it is only $72 \%$ accurate at predicting $\propto$ inoperability and lacks sensitivity in identifying patients with a poor prognosis. ${ }^{42}$ However, it may be $\stackrel{\overrightarrow{\vec{\omega}}}{\vec{\partial}}$ useful in differentiating between malignant and $\overline{0}$ inflammatory fixation once tumour fixity has been suggested by the discovery of raised serum $\alpha_{1}$ acid glycoprotein and C-reactive protein. ${ }^{43} \mathrm{CEA}$ may yet, therefore, find a role in pre-operative local tumour assessment although the relevance of this approach to clinical practice has yet to be explored prospectively.

\section{Assessment of the liver}

Accurate detection of liver metastases is important in 3 . two aspects. Firstly, a local palliative excision with S minimum hospital stay and morbidity would be $\sigma$ preferable in a patient with advanced hepatic metast- ases rather than a more extensive resection. Secondly, $\overrightarrow{\vec{A}}$ reliable methods of detecting liver metastases would $\underset{\circ}{+}$ enable treatment to be directed towards this aspect of the disease either by adjuvant regional chemotherapy $\vec{z}$ or, in suitable cases, by hepatic resection.

In 1941, Goligher was dismayed that, of $790 \stackrel{\curvearrowright}{\triangle}$ patients thought to have normal livers at surgery, liver $\overrightarrow{0}$ metastases were found at autopsy in $16 \%$ of those dying in the immediate post-operative period. ${ }^{44}$ Th idea of 'occult' liver metastases has been independently substantiated, although the incidence recently reported is nearer $30 \% .{ }^{45,46}$ The 'occult' nature of the metastasis may be due to several reasons: (i) an inaccessible liver due to adhesions from previous upper abdominal surgery; (ii) a large metastatic $\overrightarrow{3}$ deposit lying in an inaccessible part of the liver such as the posterior aspect of the right lobe; (iii) genuine small deposits which are not palpable at surgery nor readily detectable by conventional radiological 3 methods. Finlay et al. have shown CT scanning to be superior to conventional pre-operative ultrasonog-3. raphy for detecting hepatic metastases which in turn is $ᄋ$ superior to liver isotope scanning in this respect. ${ }^{45}$

Estimation of the hepatic perfusion index (HPI)윽 relies on the fact that hepatic metastases derive their $>$ blood supply preferentially from the hepatic artery. Using this technique, Leveson et al. have demon- N strated a $96 \%$ sensitivity in detecting occult liver metastases prospectively, ${ }^{46}$ but this degree of accuracy has yet to be independently substantiated.

Further advances lie in the use of intra-operative liver ultrasound. This has been shown to be extremely sensitive in detecting small tumour deposits and it is essential in order to allow minimal yet curative liver $?$ resections. ${ }^{4-49}$ There is little doubt that per-operative 0 ultrasonography will be routinely used in the not too $\overrightarrow{\mathbb{D}}$ distant future. 


\section{Prognostic staging}

DNA ploidy status can be readily determined by flow cytometry and pre-operative biopsies show a good concordance with the resected specimen. ${ }^{50}$ Although retrospective studies have all shown promising results, differing conclusions have been reached. Kokal et al. found DNA ploidy to be the single most important prognostic factor ${ }^{51}$ whilst both Armitage and Quirke found it to be of individual significance, but less so than stage.$^{52,53}$ Other centres have found it to be of no prognostic significance. ${ }^{54}$

There have been three prospective studies ${ }^{55-57}$ which have all shown a survival advantage for the DNA diploid tumours. In the studies of both Armitage and Jones this was more marked for the early stages.

Staging is always performed post-operatively on the resected specimen, usually by the Dukes' classification or one of the many modifications. ${ }^{58}$ However, this only accurately predicts the prognosis of the $15 \%$ who have an approximately $95 \%$ cure rate (Dukes' stage A) and the $10 \%$ who have a dreadful prognosis (Dukes' $C_{2}$ ). It leaves us guessing at the outcome of the intermediate $75 \%$ of cases. Jass et al. has recently proposed a major modification in staging which takes into account venous invasion, nodal spread, lymphocytic infiltration and extent of direct spread. ${ }^{59}$ It appears to be superior to the method of Dukes' inasmuch as it confidentially predicts the outcome of patients in $50 \%$ of cases. The challenge remains, however, to accurately classify patients pre-operatively.

\section{References}

1. Office of Population Censuses and Surveys Cancer Statistics registrations England and Wales HMSO, 1984, Series MB1 No. 16 p. 42.

2. McDermott, F.T., Hughes, E.S.R., Pihl, E., Johnson, W.R. \& Price, A.B. Local recurrence after potentially curative resection for rectal cancer in a series of 1,008 patients. Br J Surg 1985, 72: 34-37.

3. Slaney, G. In: Irvine, W. (ed.) Modern Trends in Surgery 3. Butterworths, Sevenoaks, 1971, pp. 69-89.

4. Parks, A.G. \& Percy, J.P. Resection and sutured coloanal anastomosis for rectal carcinoma. Br J Surg 1982, 69: 301-304.

5. Fain, S.N. \& Morganstern, L. Use of mechanical apparatus in low colo-rectal anastomosis. Arch Surg 1975, 110: 1079-1082.

6. Williams, N.S., Dixon, M.F. \& Johnston, D. Reappraisal of the $5 \mathrm{~cm}$ rule of distal excision for carcinoma of the rectum; a study of distal intramural spread and of patients' survival. Br J Surg 1983, 70: 150-154.

7. Heald, R.J., Husband, E.M. \& Ryall, R.D.H. The mesorectum in rectal cancer surgery - the clue to pelvic recurrence? Br J Surg 1982, 69: 613-616.

\section{Per-operative pelvic wall cytology and adjuvant post-operative therapy}

In a preliminary study, pelvic scrape cytology of the pelvis has been shown to be capable of detecting malignant cells remaining in the tumour bed. Moreover, $55 \%$ of the patients with positive cytology developed a local recurrence within 20 months $^{60}$ and so this may prove to be an easy, quick and inexpensive method of selecting high risk patients for adjuvant therapy.

\section{Conclusions}

There is now strong, albeit not incontrovertible, evidence that sphincter preserving surgery does not compromise overall survival or the disease free interval. It has been recommended that patients with poorly differentiated tumours should undergo APER rather than SSR. However, if we believe that APER and SSR both provide sufficiently wide resection margins, this recommendation surely becomes paradoxical, particularly as pre-operative assessment of tumour grade is unreliable.

Undoubtedly, advances in treating this disease for cure will be dependent upon improvements in the pre-operative prognostication and staging of rectal tumours as well as in development of effective adjuvant therapies.

8. Heald, R.J. \& Ryall, R.D.H. Recurrence and survival after mesorectal excision for rectal cancer. Lancet 1986, i: $1479-1482$.

9. Williams, N.S. \& Johnston, D. Survival and recurrence after sphincter saving resection and abdomino-perineal resection for carcinoma of middle $1 / 3$ of rectum. $\mathrm{Br} \mathrm{J}$ Surg 1984, 71: 278-282.

10. Phillips, R.K.S., Hittinger, R., Bresovsky, L., Fry, J.S. \& Fielding, L.P. Local recurrence following curative surgery for large bowel cancer II. The rectum and rectosigmoid. Br J Surg 1984, 71: 17-20.

11. Gillen, P. \& Peel, A.L.G. Comparison of the mortality, morbidity and incidence of local recurrence in patients with rectal cancer treated either by stapled anterior resection or abdomino-perineal resection. Br J Surg 1986, 73: 339-341.

12. Cade, D., Gallagher, P., Schofield, P.F. \& Turner, L. Complications of anterior resection of the rectum using the EEA stapling device. Br J Surg 1981, 68: 339-340.

13. Waxman, B.P. Large bowel anastomoses II. The circular staplers. Br J Surg 1983, 70: 64-67. 
14. Allen-Mersh, T.G. \& Thompson, J.P.S. Surgical treatment of colostomy complications. Br J Surg 1988, 75: 416-418.

15. Lockhart Mummery, P. Discussion on colostomy. Proc R Soc Med 1927, 20: 1466.

16. Devlin, H.B., Plant, J.A. \& Griffin, M. Aftermath of surgery for anorectal cancer. Br Med J 1971, 3: 413-418.

17. Williams, N.S. \& Johnston, D. The quality of life after rectal excision for low rectal cancer. Br J Surg 1983, 70: 460-462.

18. Lane, R.H.S. \& Parks, A.G. Function of the anal sphincters following coloanal anastomosis. Br J Surg 1977, 64: 596-599.

19. Bennett, R.C. The place of pull through operations in treatment of carcinoma of the rectum. Dis Colon Rectum 1976, 19: 420-424.

20. Rosen, C.B., Beart, R.W. Jr. \& Listrup, D.M. Local rectal carcinoma after hand sewn and stapled anastomosis. Dis Colon Rectum 1985, 28: 305-309.

21. Deddish, M.R. \& Stearns, M.W. Anterior resection for carcinoma of rectum and rectosigmoid area. Ann Surg 1961, 154: $961-966$.

22. Morson, B.C., Vaughan, E.G. \& Bussey, H.J.R. Pelvic recurrence after excision of the rectum for carcinoma. $\mathrm{Br}$ Med J 1963, 2: 13-18.

23. Nicholls, R.J., Ritchie, J.K., Wadsworth, J. \& Parks, A.G. Total excision or restorative resection for carcinoma of middle 1/3 of the rectum. Br J Surg 1979, 66: 625-627.

24. McDermott, F., Hughes, E., Pihl, E., Milne, B.J. \& Price, A. Long term results of restorative resection and total excision for carcinoma of the middle $1 / 3$ of rectum. Surg Gynecol Obstet 1982, 154: 833-837.

25. Luke, M., Kirkegaard, P., Lendorf, A. \& Christiansen, J. Pelvic recurrence after AP resection and low anterior resection for rectal cancer before and after introduction of the stapling technique. World J Surg 1983, 7: 616-619.

26. Wolmark, N. An analysis of survival and treatment failure following abdomino-perineal and sphincter saving resection for Dukes' $B$ and $C$ rectal carcinoma. A report of the NSAPB Clinical Trials. Ann Surg 1986, 204: 480-487.

27. Everett, W.G., Friend, P.J. \& Forty, J. Comparison of stapling and hand suture for left-sided large bowel anastomosis. Br J Surg 1986, 73: 345-348.

28. Nicholls, R.J., Lubowski, D.Z. \& Donaldson, D.R. Comparison of colonic reservoir and straight colo-anal reconstruction after rectal excision. $B r J$ Surg 1988, 75: 318-320.

29. Parc, R., Tirey, E., Frileaux, P., Moszkowski, E. \& Loygue, J. Resection and coloanal anastomosis with colonic reservoir for rectal carcinoma. Br J Surg 1986, 73: $139-141$.

30. Jackman, R.J. Conservative management of selected patients with carcinoma of the rectum. Dis Colon Rectum 1961, 4: 429-434.

31. Yantorno, C., Soanes, E.S., Gonder, M.J. \& Shulman, S. Studies in cryoimmunology I - The production of antibodies to urogenital tissue in the consequence of freezing tissue. Immunology 1967, 12: 395-410.

32. Bearhs, O.H. Status of fulguration and cryosurgery in the management of colonic and rectal cancer and polyps. Cancer 1974, 34: 965-968.
33. Madden, J.L. \& Kandalaft, S. Electrocoagulation: क्e primary and preferred method of treatment for cancer oĥ the rectum. Ann Surg 1967, 166: 413-419.

34. Papillon, J. Intracavity irradiation of early rectal cancer for cure. Cancer 1975, 36: 696-701.

35. Sischy, B., Hinson, E.J. \& Wilkinson, D.R. Definitive radiation therapy for selected cancers of the rectum. $\mathrm{Br}$ 尔 Surg 1988, 75: $901-903$.

36. York Mason, A.M. Rectal cancer, the spectrum of selective surgery. Proc $R$ Soc Med 1976, 69: 237-244. $\frac{\bar{s}}{1}$

37. Lock, M.R., Cairns, D.W., Ritchie, J.K. \& Lockhar居 Mummery, H.E. The treatment of early colorectal cance by local excision. Br J Surg 1978, 65: 346-349.

38. Thomas, G.D.H., Dixon, M.F., Smeeton, N.C. \& Williams, N.S. Observer variation in the histologicalgrading of rectal carcinoma. J Clin Pathol 1983, 36.్లు $385-391$.

39. Nicholls, R.J., York Mason, A. \& Morson, B.C. The् clinical staging of rectal cancer. Br J Surg 1982, 69? 404-409.

40. Beynon, J., Foy, D.M., Roe, A.M., Temple, L.N. \& Mortensen, N.J. Endoluminal ultrasound in the assess-ment of local invasion in rectal cancer. Br J Surg 1986 $\vec{\oplus}$ 73: 674-677.

41. Beynon, J., Mortensen, N.J. McC., Foy, D.M.A.오 Channer, J.L., Virjee, J. \& Goddard, P. Pre-operativeassessment of local invasion in rectal cancer: digita $R$ examination, endoluminal ultrasound or computeक्ठॄ tomography. Br J Surg 1986, 73: 1015-1017.

42. Moertel, C.G. The pre-operative carcinoembryogico antigen in the diagnosis, staging and prognosis कृo colorectal cancer. Cancer 1986, 58: 603-610.

43. Durdey, P., Williams, N.S. \& Brown, D. Serum carciñô embryonic antigen and acute phase reactant proteins ins the pre-operative detection of fixation of colorectab̆ tumours. Br J Surg 1984, 71: 881-884.

44. Goligher, J.C. The operability of carcinoma of the rectum. Br Med J 1941, ii: 393-397.

45. Finlay, I.G., Meek, D.R., Gray, H.W., Duncan, J.G. \& McArdle, C.S. Incidence and detection of occult hepatic metastases in colorectal carcinoma. $\mathrm{Br}$ Med J 1982, 2840 803-805.

46. Leveson, S.H., Wiggins, P.A., Giles, G.R., Parkin, A. \& Robinson, D.J. Deranged liver blood flow pattern in the detection of liver metastases. Br J Surg 1985, 72: $128-130$

47. Mach, I.J., Isomoto, H., Kurohijii, T. et al. Detection of unrecognised liver metastases from colorectal cancer by routine use of operative ultrasonography. Dis Colon Rectum 1986, 29: 405-409.

48. Bismuth, H., Castaing, D. \& Garden, O.J. The use of. operative ultrasound in surgery of primary liven tumours. Progress symposium Advances in Intra or operative Ultrasound. World J Surg 1987, II: 610-614. N

49. Traynor, O., Castaing, D. \& Bismuth, H. Pre-operativE ultrasonography in the survey of hepatic tumours. $\mathrm{Br}$ Surg 1988, 75: 197-202.

50. Williams, N.S., Durdey, P., Quirke, P. et al. Preoperative staging of rectal neoplasm and its impact ons clinical management. Br J Surg 1985, 72: 868-874.

51. Kokal, W., Sheibani, K., Terz, J. \& Harada, R. Tumou 5 DNA content in the prognosis of colorectal carcinoma JAMA 1986, 255: 3123-3127. 
52. Armitage, N.C., Robins, R.A., Evans, D.F., Turner, D.C., Baldwin, R.W. \& Hardcastle, J.D. The influence of tumour cell DNA abnormalities on survival in colorectal cancer. Br J Surg 1985, 72: 828-830.

53. Quirke, P., Dixon, M.F., Clayden, A.B. et al. Prognostic significance of DNA aneuploidy and cell proliferation in rectal adenocarcinomas. J Pathol 1987, 151: 285-291.

54. Melamed, M.R., Enker, W.E., Banner, P., Janev, A.J., Kessler, G. \& Daryznkiewicz, Z. Flow cytometry of colorectal cancer with three year follow up. Dis Colon Rectum 1986, 29: 184-186.

55. Jones, D.J., Moore, M. \& Schofield, P.F. Prognostic significance of DNA ploidy in colorectal cancer: a prospective flow cytometric study. Br J Surg 1988, 75: $28-33$.

56. Armitage, N.C., Wright, J., Evans, D.F., Ballantyne, K.C. \& Hardcastle, J.D. Influence of tumour cell DNA in colorectal cancer. Gut 1988, 29: A732 (Abstract).
57. Emlin, S.O., Stenling, R. \& Roos, G. Prognostic value of DNA content in colorectal carcinoma. A flow cytometric study with some methodological aspects. Cancer 1987, 60: $1282-1287$.

58. Dukes, C.E. \& Bussey, H.J.R. The spread of rectal cancer and its effects on prognosis. $\mathrm{Br} J$ Cancer 1958, 12: 309- 320 .

59. Jass, J.R., Love, S.B. \& Northover, J.M.A. A new prognostic classification of rectal cancer. Lancet 1987, i: 1303-1306.

60. Hall, C., Silverman, S.H., Moore, J., Thompson, H. \& Keighley, M.R.B. Intra-operative pelvic cytology accurately predicts those at risk of developing local recurrence of colorectal cancer. Br J Surg 1987, 74: 1149 (Abstract). 